\title{
A Complex Approach for the Design, Construction and Organizational Management of Logistics Storage and Products Processing Centers
}

Submitted 20/08/19, $1^{\text {st }}$ revision 23/09/19, $2^{\text {nd }}$ revision 29/10/19, accepted $28 / 11 / 19$

\author{
Khalyn V.G. ${ }^{1}$
}

\begin{abstract}
:
Purpose: The introduced article aims at elaborating effective solutions in terms of designing and constructing buildings and objects of a regional logistics center serviced by a 3-4 PLlevel provider taking into account practical experience in the design, construction and maintenance of logistics storage and products processing terminals that have been built.

Design/Methodology/Approach: The research of the principles of designing logistics centers substantiates the necessity of revealing and working on technological trends in the development of internal logistics along with research and development, infrastructural, planning restrictions, capacity, reserve options.

Findings: The best available equipment with the unlimited wide set of features is insufficient; each of these features needs to be applied in the working process as a single supply chain of consecutive actions.

Practical implications: The findings of this paper can be used in the practical activities of regional and federal logistics enterprises, by public and commercial entities, in the administrative activities of enterprises and organizations.

Originality/value: This research bears its determining significance in its effectiveness of practical functioning of logistics centers.
\end{abstract}

Keywords: Logistics, wholesale, innovations, development.

JEL code: $R 49$, L90.

Paper Type: Commentary note: Logistics.

${ }^{1}$ Ph.D. (Econ.), Associate Professor of the Department of Commerce and Logistics, Rostov State University of Economics, vg@ @klp.biz 


\section{Introduction}

Modern practical processes of goods distribution in the consumer market of the Russian Federation have proved the necessity and demand for such a logistics intermediary as a regional 3 PL-level logistics provider using or ready to provide services of a higher 4 PL-level.

Operation in own warehouses rather than rented is the most optimal in terms of reducing the costs of such a provider. The material, information and service flows processed by such a provider have an optimal production cost with the highest possible quality of service, which, in turn, allows optimizing these parameters not only for the depositor as a user of the logistics provider services, but what is most important, this directly ensures the quality of products and price reduction (optimization) for the final beneficiary - the retail buyer, that is, citizens.

When solving issues related to the construction of a logistics center, apart from the important tasks of choosing a geographical location, taking into account the optimal transport logistics, the primary task is to ensure the optimal use of the land, taking into account the necessary space for heavy duty, long trucks to come, turn and park. What is of utmost importance is the maximum development of the volumetric parameters of the warehouse building, entailing the minimization of unused volumes for the processes of storage and processing of cargo (Albekov et al., 2017a; 2017b; Bondarenko et al., 2017).

This article focuses on the principles of a modern approach to the design and construction of buildings and objects of a regional logistics center serviced by a 3-4 PL-level provider, considering practical experience (Khalyn, 2012).

\section{Materials and Methods}

A modern A class logistics terminal should be equipped with an addressed storage system, extended service support, imply implementing green logistics principles, using robotic narrow aisle loading equipment with an inductive forced control system. The intelligent system for automatic control of loading equipment should be fully integrated with the warehouse management system, which allows both automating technological operations for the placement and letting goods go, including combining them with one unit of equipment in the cargo alley in the shelf storage area, and minimizing human participation in decision-making and technology control. Based on our experience in the design, construction and operation of such terminals, the optimal approaches to the design of such logistics centers are described below.

The need for certain basic types of resources necessary to ensure the functioning of the warehouse building includes: 
- electricity for lighting, operation of technological and emergency equipment, charging batteries for loading and unloading equipment;

- water for fire and domestic needs;

- heat transfer medium for heating the building.

The spatial, planning and functional organization of the warehouse building of the logistics center under consideration is conditioned by the technological process of acceptance, storage, processing and assembly of the combined palletized cargo. The construction of a building with a height of 20.5 meters in the ridge, according to the external measurement, taking into account the use of the useful height of cargo storage of 17.5 meters, is a unique solution. It includes the refusal to use space frames for building re-roofing, which at a similar height can use from 4 to 5 meters of internal height indicators of a building over its entire area and significantly increase metal consumption, fire protection area, energy consumption for maintaining the internal volume of a building not used for production or other purposes.

The fire resistance of load-bearing metal structures and the building as a whole is calculated during an independent fire risk assessment to ensure safe evacuation of people in case of fire. The application of this normative measure when designing a building and allowed by the legislation of the Russian Federation lets move away from the average design indicators and requirements concluded in the Construction Norms and Regulations, allows consider all the necessary conditions to ensure safety and prevent danger to life of personnel, taking into account the specifics of the construction and operation of a particular building, and significantly reduce the production cost of its design, construction and operation.

Prevention (minimization) of damage during a fire is provided, first of all, by fire alarm systems and automatic fire extinguishing, taking into account the temperature emergency mode in a specific area of a possible fire. The risks of the custodian, including from fire or other situations leading to the damage of the assets stored, are also surely insured.

The warehouse building should be provided with the aspiration system for continuous air monitoring analyzing the temperature regime, gas composition (the presence of combustion products or smoke) and other parameters. The automatic sprinkler water fire extinguishing system that works in automatic mode is also an innovative technological solution. All security systems for personnel are integrated into a single system for collecting information, analyzing it, transmitting data to a remote control at the physical location of security services, alerting people, automatic response in critical situations, unlocking all evacuation passages blocked by the personnel access control system in the normal warehouse operation mode.

Roofing bivalve translucent smoke-proof hatches equipped with an automatic opening system are optimal for the use as a smoke removal system. These hatches are also 
used to ventilate the building and provide the necessary temperature and humidity conditions in the current operation of the warehouse. The automatic hatch control system is equipped with sensors for "rain", automatic closing of the hatch leaves in case of precipitation to prevent wet storage of stored products. The use of such a smoke removal system in case of fire, in addition to its effectiveness, allows reducing the building area used for organizing smoke removal systems to almost zero, minimizing metal consumption, energy consumption and operating costs due to the absence of ducts and electric ventilation equipment for forced air exchange. All gates for loading and unloading goods should be equipped with dock shelters, as well as dock plates.

The building should optimally consist of 2 volume zones:

- freight forwarding zone (zone of cargo acceptance and release), the minimum height of which is determined by the height of the dock gates for vehicles, the maximum height in its turn is determined by the height of the loading equipment of the main warehouse zone in the transport (minimum) position;

- the main warehouse zone of the warehouse building, for the location of the universal racking equipment for storing products, the height of which is determined by the possibility of servicing the racking equipment with loading equipment, increased by the distance necessary for the placement of fire alarm systems, fire extinguishing, lighting, ventilation and smoke removal, passing other utilities.

For example, a warehouse building having a rectangular shape can have the following zone parameters:

- Forwarding zone 1, with dimensions of $24 \times 40 \times 15$ m (length-width-height in the ridge). In this zone, at an altitude of 7 meters, there is a mezzanine with the organization of a cargo complement zone. The necessary stock of products is stored on the floor, with the organization of addresses for the location of pallets in the warehouse management system. There are sanitary facilities and amenities (toilets, a storage room for cleaning equipment) for warehouse personnel in the forwarding zone, between the entresol and the prima-goods release zone at a height of 3 meters. Their location is chosen taking into account the organization of unified flights of stairs for access to the main mezzanine of the warehouse and to these premises; - a shelf storage area of products with dimensions of 83 x 40 x $20.5 \mathrm{~m}$ (length-widthheight in the ridge);

- Forwarding zone 2, with dimensions $18 \times 45 \times 15$ m (length-width-height in the ridge). There is a mezzanine in this area at a height of 7 meters as well, on which the main administrative and utility rooms for staff are located, as well as a relatively small storage area for storing defective goods, advertising materials of depositors, the placement of sanitary rooms in the mezzanine space, similar to 1 zone. 
It is optimal to design a mezzanine above the forwarding zone to organize the cargo complement zone and (or) the location of the necessary set of office buildings for staff.

To optimize the main storage area and use loading equipment in it, the considered area has a rectangular shape, parallel to the long side of which there are alleys of racking equipment. Thus, minimization of the number of loading equipment is ensured. Besides, its operation in the cargo avenue by addressing the placement and collection of pallets, as well as optimization of the number of branches of the automatic fire extinguishing system is provided. Taking into account the above and the need to design a sufficient number of dock doors for vehicles providing high performance warehouse for acceptance of goods, it is optimal to design two forwarding zones, one on each side of the main storage area, adjacent to the smaller side of its rectangular shape.

\section{Findings}

The block-modular placement of logistics centers on the territory with a storage capacity of one such block of 10-15 thousand conventional pallets is considered to be optimal.

The delivery of cargo from the floor level of the $1^{\text {st }}$ level should be provided by the loader through the openings in the enclosure structure. Each such opening has its own address in the warehouse management system to ensure work in a single information and technological space. On the mezzanine of the building, an opening should be provided in the ceiling for the device of a telpher-type electric hoist, with the necessary load capacity, with the geometric dimensions of the platform for raising and lowering pallets. The lift shaft should be fenced with a protective fence, the lift equipped with swing-type security doors with an automatic safety lock and a wallmounted manual control panel. The presence of such a lift provides the ability to move goods and the mezzanine between the floors of the warehouse independent of mobile storage equipment.

Modern trends and technological innovations in the development of warehouse technology involve the refusal to use lead acid-base batteries and the transition to environmentally friendly and economical lithium-ion batteries. The use of this type of batteries allows avoiding the need for organizing separate charging and servicing zones for such batteries when designing a warehouse, which in addition have an increased fire hazard class and the need for separate ventilation systems. When using lithium-ion batteries, there are no emitted vapors and substances into the atmosphere when charging batteries. Battery charging is allowed in the common area based on the Conclusion of the Academy of the State Fire Service of the Ministry of Emergency Situations of Russia. 
Based on the above issues and to optimize the use of the warehouse area, it is supposed to charge lithium-ion storage batteries of warehouse equipment in the loading and unloading zone without removing and replacing them for recharging. This is ensured by the short charging time of this type of battery (a full cycle of 2 hours, with the possibility of discrete recharging at any time), which is ensured during technological interruptions in the operation of equipment and interruptions in the work of personnel, even with the 24-hour warehouse.

\section{Discussion}

Technological innovations in the course of cargo storage and processing include the following procedures:

- the procedure for the acceptance of goods, which includes unloading the goods from the transport unit and moving it to the acceptance zone, identification and labeling, bringing the goods to the standard of storage, quality control of the goods received, recounting of goods;

- marking of goods (in case of the impossibility to use or have factory marking), using bar coding, which allows unique identifying of goods at all stages of storage and minimizing the likelihood of error;

- the placement of goods on shelving equipment, taking into account the zones fixed as a result of the analysis, can reduce the cost of subsequent goods selection and processing;

- the procedure for goods shipment, which includes the preparation of a package of shipping documents, identification, transfer to the forwarding zone, goods quantity and quality control, loading into a transport unit.

Goods are stored on universal racking equipment with maximum use of the height and volume of the warehouse. The equipment used allows placing goods at a height of up to $15 \mathrm{~m}$ along the bottom of the upper tier of storage and, in fact, bringing the useful used storage height to 17.5 meters.

Universal racking equipment designed for the use in storage objects where mechanized maintenance of the warehouse is conducted is used as storage equipment at the object put into operation.

The increased bearing capacity of the company's products is achieved by the fact that the beams are fastened to the frames, according to a diagon hook scheme, which is the best fastening option. Together with high load capacity, the diagon hook scheme significantly reduces the risk of collapse of shelving from exposure to loading equipment, accompanied by the deformation of rack frames and beams. The beam is connected to the frame without a gap, which gives additional rigidity to the rack structure. The closed profile of the rack frames and eight stiffening ribs give increased bending and torsional rigidity to the rack frames. 
This type of shelving complies with the best European models and has two certificates - Russian and international TUV NORD ISO 9001: 2008, as well as a positive sanitary and epidemiological opinion of the Federal Surveillance Service. Product certificates passed all international tests of TUV ISO 9001: 2008. The load on the section with a distance between tiers of $2250 \mathrm{~mm}$ was up to $27100 \mathrm{~kg}$.

To place cargo in the shelf storage structures for optimizing the use of warehouse space, it is advisable to use narrow-aisle stackers, which are a type of storage equipment that are successfully used for operation in storage rooms. Its technical characteristics make it possible to efficiently use a high-rack stacker in warehouses, in the activities of logistics operators, production enterprises for the storage of all types of pallet goods.

The main technological initiative regarding warehouse equipment is the use of a model design that allows obtaining individual lifting parameters by means of several modules of lifting frames and moving pallets to a height of up to 15 meters. Stackers of this type are equipped with a lifting cabin for the operator, which allows for the placement and packaging of goods located at this height.

Tall stackers can be equipped with swivel or telescopic forks. Due to this, the operator has the ability to service the shelves located to the right and left of him/her. Thanks to the functional rotary forks, it becomes possible to solve the maximum number of storage tasks even in narrow shelving aisles. Such universal technical equipment of the stacker allows the goods to be shifted to the side, from depth to the edge of the shelf, and it can also be used to slide the cargo into the shelf. By using this narrowaisle warehouse equipment in production, labor productivity is increased, a high level of cargo turnover is ensured, and operating time is significantly saved, and increased operational safety is achieved.

The use of trolleys with low cargo lifting heights, which are designed to optimize the process of transporting products in warehouses, logistics centers, wholesale and industrial markets, is also a relevant solution to innovative warehouse logistics. Equipment is distinguished by its reliability, safety; it is convenient to operate it. This ensures the widespread use of this variety of equipment in warehouse logistics along with loaders, stackers, etc. Such trolleys make it possible to transport goods with various, including non-standard, dimensions.

Modern trolleys of leading manufacturers allow lifting loads to a height of $130 \mathrm{~mm}$, they are reliable, safe, and have high quality, convenience and ease of use. The trolley can lift cargoes weighing up to $2000 \mathrm{~kg}$. The lower surface of the frame and the sharpheaded ends of the forks do not allow the trolley to get stuck in the aisles. Due to the rounded corners of the platform, the hydraulic trolley can back out of the truck. The vehicle suspension of the central wheel evenly distributes the load on the equipment and provides optimal traction, the brake system includes two independent circuits. 
Modern warehouse equipment is equipped with traction (working) maintenance-free rechargeable lithium-ion (LiFePO4) batteries based on lithium-ion rechargeable cells, allowing fractional charging cycles at any charge level. Charging time up to 100\% when fully discharged is $120 \mathrm{~min}$. The charger is located on the wall or column of the warehouse. The charge is conducted by switching the plug of the device with the battery. The charger turns on and off automatically. There are no emitted vapors and substances into the atmosphere. Charging the batteries is allowed in the common room on the basis of the Conclusion of the Academy of the State Fire Service of the Ministry of Emergency Situations of Russia. Such batteries are intended as a source of energy in electric vehicles and energy storage devices in energy systems, as well as in storage equipment (stackers, reach trucks, loaders, trolleys, etc.), when installed and used correctly, do not require the installation of local exhaust ventilation (ventilation umbrella) devices above them.

\section{Conclusion}

The main principle coming first and which should be followed when designing logistics centers is technology or internal logistics. In this case, the issue is about innovative technologies of the latest generation and promising developments that will become in demand in the near future. Everything else is built into technological innovation and its required functionality. Appropriate conditions, material and technical base, equipment, machines are formed, the functional of employees, job responsibilities and staffing are established with the adjustment to it.

The second not least important aspect of the logistics business processes in the warehouse is their complexity. It is not enough to have the most advanced equipment with an unlimited wide range of capabilities; each of these capabilities needs to be involved in the work process as a single logistics chain of sequential actions.

The third aspect of business processes and an equally important task is to minimize all types of losses. For example, it is related to the absence of blank runs of equipment when placing products. Serving the incoming and outgoing cargo flows, the enterprise should make the storage area zoned so that the equipment does not move from rack to rack, picking up on a pallet or box. It is necessary to form a party consisting of different categories of goods in one zone. Moreover, a necessary and effective solution is the actual connection of the incoming and outgoing cargo flows, when the same unit of loading equipment, leaving to place the outgoing cargo, simultaneously distributes the incoming cargo flow to storage locations.

The principles of construction and organization of work of a modern warehouse logistics center for goods storage and processing described in this paper are aimed at optimizing and reducing costs in its design, construction and optimal operation, taking into account the requirements of current legislation, as well as current and future needs of the logistics services market. 


\section{References:}

Albekov, A.U., Israilova, E.A., Polubotko, A.A., Matishov, G.G., Parkomenko, T.V. 2017. Green logistics in the south of Russia: the potential of transport corridors of the three elements. Green Economy: Modernization of the socio-economic system of the South of Russia, Rostov-on-Don.

Albekov, U.A., Parkhomenko, V.T., Polubotko, A.A. 2017. Green Logistics in Russia: The Phenomenon of Progress, Economic and Environmental Security. European Research Studies Journal, 20(1), 13-21.

Bondarenko, A.V., Parkhomenko, V.T., Erokhina, B.T., Guzenko, V.N. 2017. Marketing and Logistic Instrumentarium of Activation of Inter-Country Cooperation of Russia and Solving the Issue of Import Substitution. European Research Studies Journal, 20(1), 105-116.

Khalyn, V.G. 2012. Innovative mechanisms for the functioning of the logistics infrastructure of the regional distribution network. Bulletin of Rostov State University of Economics, 4(40). 